\title{
The Characterization of Non-Porous Surfaces by a Combination of the BET and the Dubinin-Radushkevich-Kaganer (DRK) Theories
}

\author{
Deirdre Hugi-Cleary, Sandra Wermeille, and Fritz Stoeckli*
}

\begin{abstract}
Dedicated to Professor Jean-Baptiste Donnet (UHA, Mulhouse) on his 80th birthday
Abstract: The characterization of non-porous surfaces by the BET and the DRK techniques should be complementary. However, the monolayer capacities $\mathrm{N}_{\mathrm{am}}$ obtained by these techniques may be different, with trends for the adsorption of simple molecules on a given surface. Assuming that the BET monolayer is correct, its use in the DRK equation leads to exponents $n$ different from the standard value $n=2$. This exponent is directly related to the width of $\chi(\varepsilon)$, the distribution of the gas-solid adsorption energy $\varepsilon$ for a given system. Therefore, the analysis based on an extended DRK equation leads to information on the heterogeneity of the surface. For example, the data for adsorption of simple molecules physisorbed on a non-porous silica, on the (111) face of rhombic sulphur and on graphitised carbon blacks lead to average exponents of 1.2, 2.0 and 2.2 respectively, with specific scaling factors $\beta$. In the case of nitrogen adsorbed on $\mathrm{SiO}_{2}$, the value $n=1.8$ suggests the presence of specific interactions.
\end{abstract}

Keywords: Dubinin and BET theories · Energy distribution · Non-porous solids · Vapour adsorption

\section{Introduction}

Traditionally, non-porous surfaces can be characterized by the well-known BET theory [1]. With the help of simple adsorptives such as nitrogen at $77 \mathrm{~K}$ or benzene near room temperature, this approach, based on multilayer adsorption, leads to the surface area of the solid, $\mathrm{S}_{\mathrm{BET}}\left(\mathrm{m}^{2} \mathrm{~g}^{-1}\right)$. In spite of the shortcomings of the underlying theory, this approach provides a good estimate for the surface area, for example with the help of nitrogen adsorbed at $77 \mathrm{~K}$ or organic vapours near room temperature. It is assumed that the surface is homogeneous and lateral interactions are neglected, but the heterogeneous character of real surfaces and the increase in neighbourhood with increasing adsorption have a compensating

${ }^{*}$ Correspondence: Prof. F. Stoeckli Institut de Chimie, Université de Neuchâtel Av. de Bellevaux 51

CH-2007 Neuchâtel

Tel.: +41327182425

Fax: +4132 7182511

E-Mail: Fritz.Stoeckli@unine.ch effect. Consequently, the equivalent monolayer capacity of the surface, $\mathrm{N}_{\mathrm{am}}$ (BET) $\left(\mathrm{mmol} \mathrm{g}^{-1}\right)$ is in relatively good agreement with the effective surface area determined by other techniques [2].

In 1957, an entirely different approach was proposed by Kaganer [3-6], as an extension of Dubinin's theory [7-9]. The latter had shown that the volume filling of microporous (nanoporous) solids such as activated carbons and zeolites could be explained in terms of the thermodynamic potential $A=R T \ln \left(p_{s} / p\right)$. As discussed below, this led to the so-called DubininRadushkevich-Kaganer (DRK) equation [1][10].

The BET and the DRK approaches apply to different domains of relative pressures $\mathrm{p} / \mathrm{p}_{\mathrm{s}}$, but they should provide complementary and self-consistent information on the surface under investigation. However, as pointed out by different authors [1][10-12], the monolayer capacities $\mathrm{N}_{\mathrm{am}}\left(\right.$ BET) and $\mathrm{N}_{\mathrm{am}}$ (DRK) may often show systematic differences. Depending on the type of surface, for the same series of simple and non-specific adsorbates, the ratio
$\mathrm{N}_{\mathrm{am}}(\mathrm{DRK}) / \mathrm{N}_{\mathrm{am}}$ (BET) can be larger or smaller than unity. This may cast doubts on the DRK approach, since the surface areas derived from $\mathrm{N}_{\mathrm{am} \text { BET }}$ appear to be closer to reality, at least for type II isotherms.

In the present study we show that the apparent shortcoming of the DRK approach can be lifted by considering a variable exponent in the fundamental equation, usually taken as equal to two. This is not surprising, in view of the fact that this quantity reflects the heterogeneity of the surface with respect to the adsorption energy distribution $\chi(\varepsilon)$ [9][10]. The extension of the DRK equation, proposed here, has been tested for the adsorption of simple molecules on nonporous carbon blacks, sulphur and silica.

\section{Theory}

Following Polanyi's idea [13], Dubinin and his coworkers suggested in 1947 that the adsorption of simple vapours by microporous carbons could be described by a relatively simple and elegant expression known as the Dubinin-Radushkevich (DR) 
equation. At a later stage (1971), this approach was further improved to include other microporous solids such as zeolites, for example. This led to the so-called Dubinin-Astakhov (DA) equation [7-9]

$\mathrm{N}_{\mathrm{a}}(\mathrm{T} ; \mathrm{p})=\mathrm{N}_{\mathrm{ao}} \exp \left[-(\mathrm{A} / \mathrm{E})^{\mathrm{n}}\right]$

where

$\mathrm{A}=\mathrm{RT} \ln \left(\mathrm{p}_{\mathrm{s}} / \mathrm{p}\right)$

$\mathrm{N}_{\mathrm{ao}}$ is the limiting amount adsorbed in the pores and, provided that no molecular sieve effects are present, the total volume of the micropores is $\mathrm{W}_{\mathrm{o}}=\mathrm{N}_{\mathrm{ao}} \mathrm{V}_{\mathrm{m}}, \mathrm{V}_{\mathrm{m}}$ being the molar volume of the condensed adsorbate (vapour) at the given temperature. For typical carbons, exponent $\mathrm{n}$ is close to 2 , which corresponds to the original DR equation. On the other hand, in the case of zeolites, $\mathrm{n}$ may take values between 1.5 and 4-5, depending on the size and the chemistry of their cavities. The quantity E, called the characteristic energy of adsorption, depends on both the solid and the adsorbate. If no specific interactions are present, a scaling factor $\beta$, called the affinity coefficient, can be introduced for the various adsorbates, with benzene as a reference and $E=\beta E_{o}$ [14]. In view of the simplicity of its parameters, it follows that Eqn (1) provides a very useful basis for the prediction of adsorption under static and dynamic [15] conditions.

The validity of Dubinin's theory requires the temperature invariance of parameters $\mathrm{E}$ and $\mathrm{n}$, which is reflected by the linearity of the plot of $\ln \left(\mathrm{N}_{\mathrm{a}} / \mathrm{N}_{\mathrm{ao}}\right)$ versus $\mathrm{A}^{\mathrm{n}}$ for different temperatures and pressures. With specific values of $\beta$, relative to a given adsorbate (for example benzene or nitrogen), one obtains a single plot for the data corresponding to different molecules physisorbed on a given solid.

Kaganer [3-6] suggested describing the adsorption of simple molecules by nonporous solids based on an expression similar to the DA equation

$\mathrm{N}_{\mathrm{a}}(\mathrm{T} ; \mathrm{p})=\mathrm{N}_{\mathrm{am}}(\mathrm{DRK}) \exp \left[-(\mathrm{A} / \mathrm{E})^{2}\right]$

In this expression, later known as the Dubinin-Radushkevich-Kaganer (DRK) equation [1][10][11], $\mathrm{N}_{\mathrm{am}}$ (DRK) represents the monolayer capacity. It is obtained by extrapolation, since multilayer adsorption gradually takes over with increasing pressure. This leads to an upward deviation in the classical plot of $\ln \left(\mathrm{N}_{\mathrm{a}}\right)$ versus $\mathrm{A}^{2}$ and the choice of the linear section may become difficult (see[10] and references therein). The limiting value, $\mathrm{N}_{\mathrm{am}}(\mathrm{DRK})$ is related to the surface area of the solid by

$$
\mathrm{S}_{\mathrm{DRK}}\left(\mathrm{m}^{2} \mathrm{~g}^{-1}\right)=\mathrm{N}_{\mathrm{am}}(\mathrm{DRK}) \cdot \mathrm{A}_{\mathrm{m}} \cdot \mathrm{N}_{\mathrm{Av}}
$$

where $\mathrm{A}_{\mathrm{m}}$ and $\mathrm{N}_{\mathrm{av}}$ are respectively the molecular surface area [1][16] and Avogadro's number. The same equation applies in the BET approach but, due to multilayer adsorption, $\mathrm{N}_{\mathrm{am}}$ (BET) is an equivalent monolayer capacity. It is usually found in the range $0.05<\mathrm{p} / \mathrm{p}_{\mathrm{s}}<0.20-0.30[1]$.

Obviously, the characteristic energy E of Eqn. (1) must be temperature invariant, at least over a reasonable range, and one should obtain specific affinity coefficients for the various adsorbates, one of them being taken as a reference.

It can be shown [9][10], that Eqn. (1) corresponds, to a good first approximation (the so-called condensation approximation), to an underlying normalized distribution of the gas-solid adsorption energy $\varepsilon$,

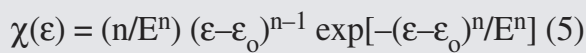

$\varepsilon_{\mathrm{o}}$ is the lower bound of the energy of adsorption, which depends on the choice of the local isotherm [10]. However, in the case of microporous carbons, a reasonable guess would be the limiting value of the adsorption energy on the basal plane of graphite, $-43 \mathrm{~kJ} \mathrm{~mol}^{-1}$ and $-10 \mathrm{~kJ} \mathrm{~mol}^{-1}$ for benzene and nitrogen, respectively [17]. It appears that, for a given system, exponent $\mathrm{n}$ is related to the width of the distribution $\chi(\varepsilon)$ and it reflects its heterogeneity (the distribution sharpens as $\mathrm{n}$ varies from $\mathrm{n}=1.5$ to $\mathrm{n}=3$ ). An arbitrary value $\mathrm{n}=2$, corresponds therefore to an 'average' distribution. Furthermore, the values of $\mathrm{E}$ of the various adsorptives are related by an affinity coefficient $\beta$, one of them being taken as a reference (usually benzene). Eqn. (5) can be tested by examining the variation of the differential heat of adsorption or the enthalpy of immersion, both derived from Eqn. (1) by a rigorous thermodynamic treatment [8-9].

In the case of microporous carbons, the value $n=2$, originally suggested by Dubinin, reflects a fixed distribution, describing standard materials. However, it appeared that in the case of very homogeneous micropores (true molecular sieves) $n=3$ gave better results, whereas values as low as 1.5 had to be used with very heterogeneous carbons [8][18].

This approach can be transposed in a straightforward manner to non-porous materials, where the surface also presents variable energy distributions $\chi(\varepsilon)$. In the case of non-porous carbons, $\mathrm{E}$ is obviously lower than for microporous carbons (respectively $10-11 \mathrm{~kJ} \mathrm{~mol}^{-1}[12]$ and 15 to $30 \mathrm{~kJ} \mathrm{~mol}^{-1}$ [8][18] for benzene). Exponent $\mathrm{n}=2$, used in the DRK Eqn. (3) corresponds to a fixed type of distribution (5), which may not apply to all surfaces. Therefore, allowing for a variable exponent $\mathrm{n}$ will take into account the true width of the energy distribution $\chi(\varepsilon)$ on the surface. By analogy with the case of activated carbons and other nanoporous structures, a more flexible DRK equation would be

$$
\mathrm{N}_{\mathrm{a}}(\mathrm{T} ; \mathrm{p})=\mathrm{N}_{\mathrm{am}} \exp \left[-(\mathrm{A} / \mathrm{E})^{\mathrm{n}}\right]
$$

This equation contains three variables, $\mathrm{N}_{\mathrm{am}}, \mathrm{n}$ and $\mathrm{E}$. From a mathematical point of view, it should be possible to obtain them from a best fit of the adsorption data to Eqn. (6). However, the gradual transition to multilayer adsorption introduces deviations in the data to be analysed and the domain of linearity of a logarithmic plot of Eqns (3) and (6) may present difficulties. As a general rule, this domain does not extend beyond a surface coverage $\mathrm{N}_{2} / \mathrm{N}_{\text {am }}$ of approximately $0.3-0.5$. As pointed out by different authors [10-11] and shown below, the choice of the linear section leads to uncertainties in $\mathrm{N}_{\mathrm{am}}$ (DRK). One may therefore be tempted to assume that $\mathrm{N}_{\mathrm{am}}(\mathrm{DRK})=$ $\mathrm{N}_{\mathrm{am}}$ (BET) and determine exponent $\mathrm{n}$ (and implicitly E) by a best fit. The proposed working equation, which offers more flexibility, is therefore

$\mathrm{N}_{\mathrm{a}}(\mathrm{T} ; \mathrm{p})=\mathrm{N}_{\mathrm{am}}(\mathrm{BET}) \exp \left[-(\mathrm{A} / \mathrm{E})^{\mathrm{n}}\right] \quad(7)$

Moreover, data analysis (see below) shows that adjusting parameter $\mathrm{n}$ may increase the quality of the fit considerably, by extending the range of linearity in the logarithmic plot.

The approach based on Eqn. (7) is also an alternative to the procedure used by some authors [10][19][20] who replace the saturation pressure $\mathrm{p}_{\mathrm{s}}$ found in the thermodynamic potential $\mathrm{A}=\mathrm{RT} \ln \left(\mathrm{p}_{\mathrm{s}} / \mathrm{p}\right)$ by an adjustable pressure $p_{m}$, while keeping exponent $\mathrm{n}=2$. Variable pressures $\mathrm{p}_{\mathrm{m}}$ or exponents $\mathrm{n}$ may both improve the fits, but they have different physical meanings, in particular if $\mathrm{p}_{\mathrm{m}}$ turns out to be larger than $\mathrm{p}_{\mathrm{s}}$. It must also be pointed out that the value of exponent $\mathrm{n}$ can also be tested, formally at least, by using independent information on the adsorption energy distribution, based either on the study of adsorption potentials by computer simulations [21][22], or by calorimetry [8][9].

\section{Results and Discussion}

By using standard gravimetric and/or volumetric adsorption equipment [1][12], the following systems were investigated in the relative pressure range $10^{-4}-10^{-3}<\mathrm{p} / \mathrm{p}_{\mathrm{s}}$ $<0.7-0.8$. 
1) On Cabosil, a non-porous silica gel: $\mathrm{N}_{2}(77 \mathrm{~K}), \mathrm{CH}_{2} \mathrm{Cl}_{2}(293,313 \mathrm{~K}), \mathrm{C}_{6} \mathrm{H}_{6}$ $(293,303,313 \mathrm{~K}), \mathrm{CCl}_{4}(293,310 \mathrm{~K})$. We also considered $\mathrm{N}_{2}(77 \mathrm{~K})$ on Nucleosil-300 and Nucleosil-1000. The non-porous character of these solids was tested with the help of the reference isotherm on Fransil [1], the data from which was also used in the present analysis.

2) On graphitised carbon blacks Hoechst [12] and Vulcan 3-G [23]: $\mathrm{N}_{2}$ (77 $\mathrm{K}), \mathrm{CO}_{2}(253,273 \mathrm{~K}), \mathrm{CH}_{2} \mathrm{Cl}_{2}(293 \mathrm{~K})$, $\mathrm{C}_{6} \mathrm{H}_{6}(282,293,311,325 \mathrm{~K}), \mathrm{CCl}_{4}(293$, $305 \mathrm{~K})$.

3) On the (111) face of rhombic sulphur, $\mathrm{S}_{\alpha}$ [21][22][24]: $\mathrm{N}_{2}(77,86 \mathrm{~K}), \operatorname{Ar}(77,87$ $\mathrm{K}), \mathrm{CH}_{4}(80 \mathrm{~K})$, neo- $\mathrm{C}_{5} \mathrm{H}_{12}(253,263,273$ $\mathrm{K})$.

The classical BET analysis of the nitrogen isotherms, based on the standard molecular area $\mathrm{A}_{\mathrm{m}}\left(\mathrm{N}_{2} ; 77 \mathrm{~K}\right)=16.2 \cdot 10^{-20} \mathrm{~m}^{2}$ [1] led to $\mathrm{S}_{\mathrm{BET}}$ areas of $210 \mathrm{~m} \mathrm{~g}^{-1}$ (Cabosil), $0.060 \mathrm{~m} \mathrm{~g}^{-1}$ (sulphur $\mathrm{S}_{\alpha}$ ), $53 \mathrm{~m} \mathrm{~g}^{-1}$ (Hoechst) and $73 \mathrm{~m} \mathrm{~g}^{-1}$ (Vulcan 3G) (see Table). The BET surface areas obtained with the other adsorptives, using the corresponding molecular surface areas $A_{m}[16]$, led to similar values. For example, in the case of Cabosil, the overall average for the four vapours is $208 \pm 4 \mathrm{~m}^{2} \mathrm{~g}^{-1}$ (eight different results).

In the case of benzene adsorbed on $\mathrm{Ca}$ bosil, at 293, 303 and $313 \mathrm{~K}$, the logarithmic plot of the DRK Eqn. (3), $\ln \left(\mathrm{N}_{\mathrm{a}}\right)$ versus $\mathrm{A}^{2}$ shows a good overlap for the three temperatures (Fig. 1). This means that the requirement for temperature invariance is fulfilled, at least over a certain range of temperatures. However, as pointed out by different authors, for example [10-12], the choice of the linear section in a DRK plot is not easy, due to the fact that multilayer adsorption gradually sets in. A reasonable choice leads to the line shown on the graph and its extrapolation leads to the monolayer capacity $\mathrm{N}_{\mathrm{m}}(\mathrm{DRK})=0.53 \mathrm{mmol} \mathrm{g}^{-1}$. The ratio $\mathrm{N}_{\mathrm{am}}(\mathrm{DRK}) / \mathrm{N}_{\mathrm{am}}(\mathrm{BET})$ is therefore 0.65 , which is too small. The true limit, $\mathrm{N}_{\mathrm{am}}($ BET $)=0.84 \mathrm{mmol} \mathrm{g}^{-1}$ can only be reached by a short and arbitrary portion in the graph, which neglects part of the low pressure range. This suggests, in the present case, some inconsistencies in the DRK Eqn. (3). On the other hand, if one assumes that $\mathrm{N}_{\mathrm{am}}(\mathrm{BET})$ is the correct limit, a best fit can be obtained with the help of a variable exponent $n$, as expressed by Eqn. (7). As shown in Fig. 1, one obtains $\mathrm{n}=1.2$ and a value $\mathrm{E}_{\mathrm{C} 6 \mathrm{H} 6}=5.61 \mathrm{~kJ} \mathrm{~mol}^{-1}$. This approach takes into account the adsorption at low relative pressures, which corresponds effectively to the sub-monolayer region. The break from linearity corresponds to a surface coverage $\mathrm{N}_{\mathrm{a}} / \mathrm{N}_{\mathrm{am}}$ of approximately
0.3 . This probably justifies the use of the modified DRK Eqn. (7) in the case of benzene.

A similar pattern is observed for $\mathrm{CH}_{2} \mathrm{Cl}_{2}$ and $\mathrm{CCl}_{4}$, with ratios of 0.73 and 0.76 , respectively. Applying the same procedure, one obtains similar values for exponent $\mathrm{n}$, respectively $1.25\left(\mathrm{CH}_{2} \mathrm{Cl}_{2}\right)$, $1.10\left(\mathrm{CCl}_{4}\right)$. This means that the adsorption of $\mathrm{C}_{6} \mathrm{H}_{6}, \mathrm{CH}_{2} \mathrm{Cl}_{2}$ and $\mathrm{CCl}_{4}$ on Cabosil can be fitted, with a good approximation, to Eqn. (7). As shown in Fig. 2, one obtains a single representation of $\ln \left(\mathrm{N}_{\mathrm{a}} / \mathrm{N}_{\mathrm{am}}\right)$ versus $\left(\mathrm{A} / \mathrm{E}_{\mathrm{C} 6 \mathrm{H} 6}\right)^{1.2}$, where $\beta=\mathrm{E} / \mathrm{E}_{\mathrm{C} 6 \mathrm{H} 6}$ is a scaling factor relative to benzene. In the case of Cabosil, $\mathrm{E}_{\mathrm{C} 6 \mathrm{H} 6}\left(\mathrm{SiO}_{2}\right)=5.61 \mathrm{~kJ} \mathrm{~mol}^{-1}$, $\beta_{\mathrm{CCl} 14}=0.75$ and $\beta_{\mathrm{CH} 2 \mathrm{Cl} 2}=0.85$. These factors are different from those observed in the case of activated carbons [8][9][14]. In particular, $\beta_{\mathrm{CH} 2 \mathrm{Cl} 2}=0.85$ is higher, which suggests the presence of specific interactions.

In the case of Cabosil, only nitrogen is in agreement with the DRK Eqn. (3), with a ratio $\mathrm{N}_{\mathrm{am}}(\mathrm{DRK}) / \mathrm{N}_{\mathrm{am}}$ (BET) close to unity. The best fit corresponds to $\mathrm{n}=1.8$ (see Fig. 2). The data obtained for other non-porous silicas such as Fransil [1], Nucleosil-300 and Nucleosil-1000 fall on the same line as Cabosil, which indicates a common pattern for non-porous and untreated silicas. The relatively high value of the characteristic energy $\mathrm{E}_{\mathrm{N} 2}\left(\mathrm{SiO}_{2}\right)=4.62 \mathrm{~kJ} \mathrm{~mol}^{-1}$ with respect to $\mathrm{E}_{\mathrm{C} 6 \mathrm{H} 6}\left(\mathrm{SiO}_{2}\right)=5.61 \mathrm{~kJ} \mathrm{~mol}^{-1}$, a ratio of 0.8 , strongly suggests the presence of specific interactions between nitro- gen and the silica surface (In the case of carbons, where there are no specific interactions, the ratio is only 0.33 [14]).

Our results suggest that, with the exception of nitrogen, the energy distribution $\chi(\varepsilon)$ for $\mathrm{C}_{6} \mathrm{H}_{6}, \mathrm{CH}_{2} \mathrm{Cl}_{2}$ and $\mathrm{CCl}_{4}$ is probably broader than implied by the DRK equation. In the case of benzene, the low value of $n$ is not too surprising and it is consistent with the adsorption of this vapour by the microporous silica $G-200$. As reported by Pendleton [25][26], the traditional plot of $\ln \left(\mathrm{N}_{\mathrm{a}}\right)$ versus $\mathrm{A}^{2}$ shows an upward curvature. This was treated as a sum of two DR equation with characteristic energies $\mathrm{E}_{1}=13.2 \mathrm{~kJ} \mathrm{~mol}^{-1}$ and $\mathrm{E}_{2}=6.3 \mathrm{~kJ} \mathrm{~mol}^{-1}$. However, as suggested by Dubinin and Stoeckli [18], a variable exponent $n$ often seems more appropriate, as it corresponds to a continuous energy distribution. In the case of $G-200$, a new analysis suggests that $\mathrm{n}=1.5$ and $\mathrm{E}\left(\mathrm{C}_{6} \mathrm{H}_{6}\right)=10.2 \mathrm{~kJ} \mathrm{~mol}^{-1}$. In view of Eqn. (5), this indicates that the adsorption energy distribution is relatively heterogeneous. Therefore, it is not too surprising to find a similar heterogeneity on the open surface of Cabosil with $\mathrm{n}=1.2$, but with a lower value of $\mathrm{E}\left(\mathrm{C}_{6} \mathrm{H}_{6}\right)=5.61 \mathrm{~kJ} \mathrm{~mol}^{-1}$.

It is also interesting to point out that nitrogen adsorption by various microporous silicas follows closely the Dubinin Eqn. (1) with exponent $n=2$, as observed for nonporous silicas. As expected, the characteristic energies $\mathrm{E}_{\mathrm{N} 2}=5-5.5 \mathrm{~kJ} \mathrm{~mol}^{-1}$ are somewhat higher. This establishes a coherent

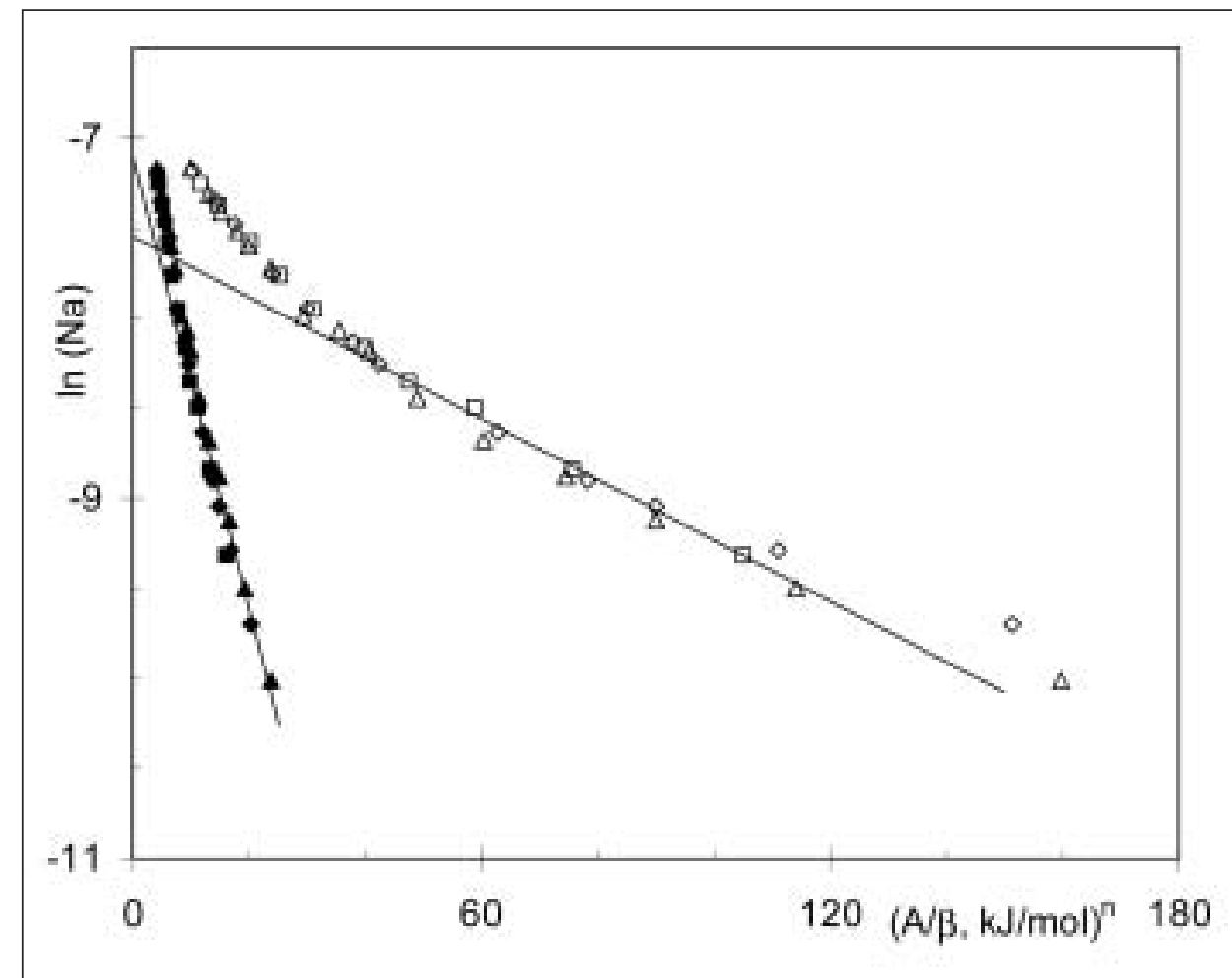

Fig. 1. The adsorption of $\mathrm{C}_{6} \mathrm{H}_{6}$ by Cabosil at $293 \mathrm{~K}(\diamond), 303 \mathrm{~K}(\square)$ and $313 \mathrm{~K}(\triangle)$ as a function of $A^{2}$ (open symbols) and $A^{1.2}$ (filled symbols). Exponent 1.2 is obtained from a best fit to Eqn. (7), assuming that $\mathrm{N}_{\mathrm{am}}(\mathrm{DRK})=\mathrm{N}_{\mathrm{am}}(\mathrm{BET})=0.84 \mathrm{mmol} \mathrm{g}^{-1}$. 


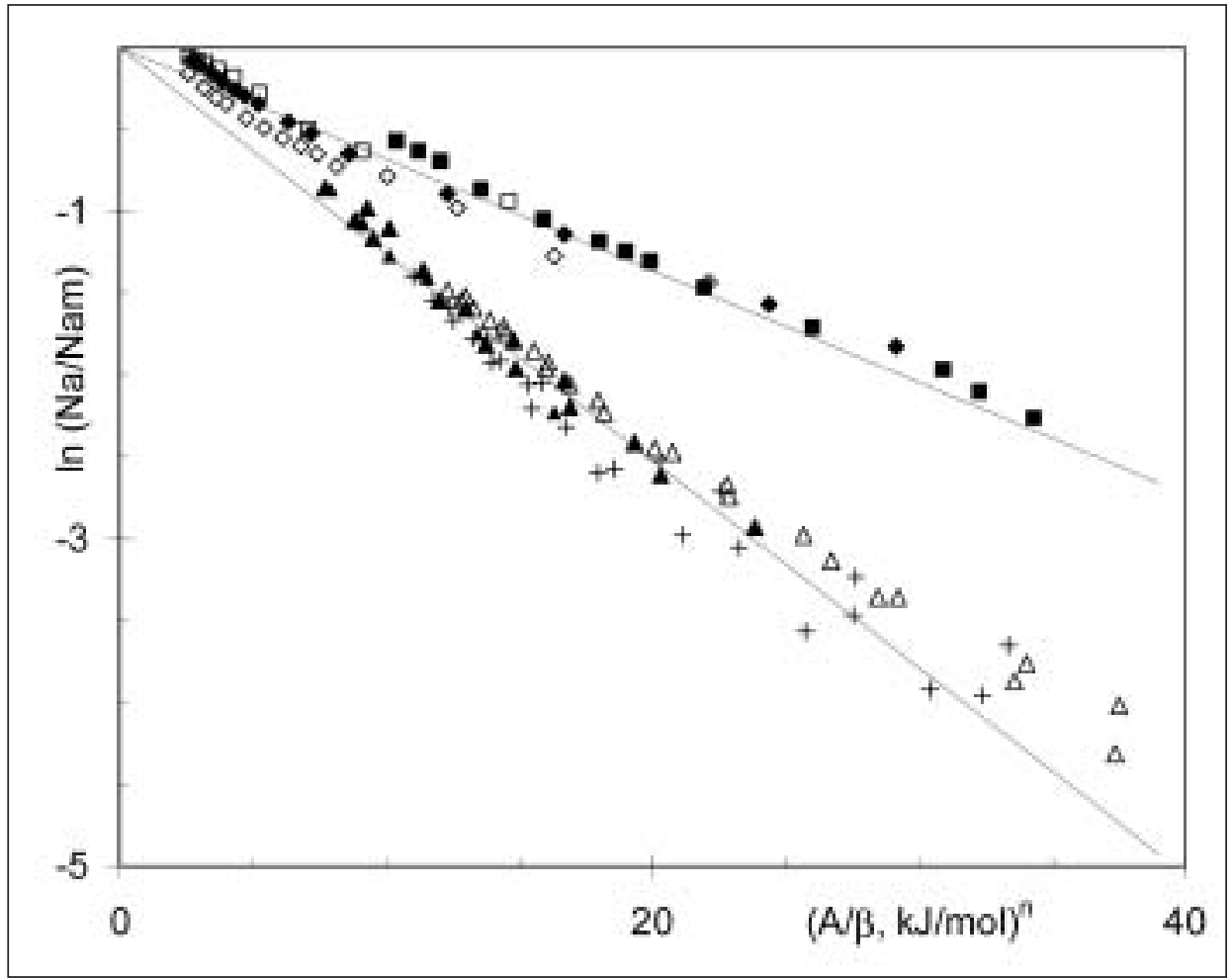

Fig. 2. The adsorption of $\mathrm{N}_{2}(77 \mathrm{~K})$ on Cabosil, $(\square)$; Fransil $(\square)$, Nucleosil-300 $(\diamond)$ and Nucleosil-1000 ( $) ; \mathrm{C}_{6} \mathrm{H}_{6}(293,303,313 \mathrm{~K})(\mathbf{\Lambda}), \mathrm{CH}_{2} \mathrm{Cl}_{2}(293,313 \mathrm{~K})(\triangle)$ and $\mathrm{CCl}_{4}(293,310 \mathrm{~K})(+)$ on Cabosil; $\mathrm{CCl}_{4}(293 \mathrm{~K})(+)$ on Fransil. For nitrogen exponent $\mathrm{n}=1.8$ and $\mathrm{E}_{\mathrm{N} 2}(77 \mathrm{~K})=4.62 \mathrm{~kJ} \mathrm{~mol}^{-1}$. For the other adsorptives $\mathrm{n}=1.2$ and $\mathrm{E}_{\mathrm{C} 6 \mathrm{H} 6}=5.61 \mathrm{~kJ} \mathrm{~mol}^{-1}$.

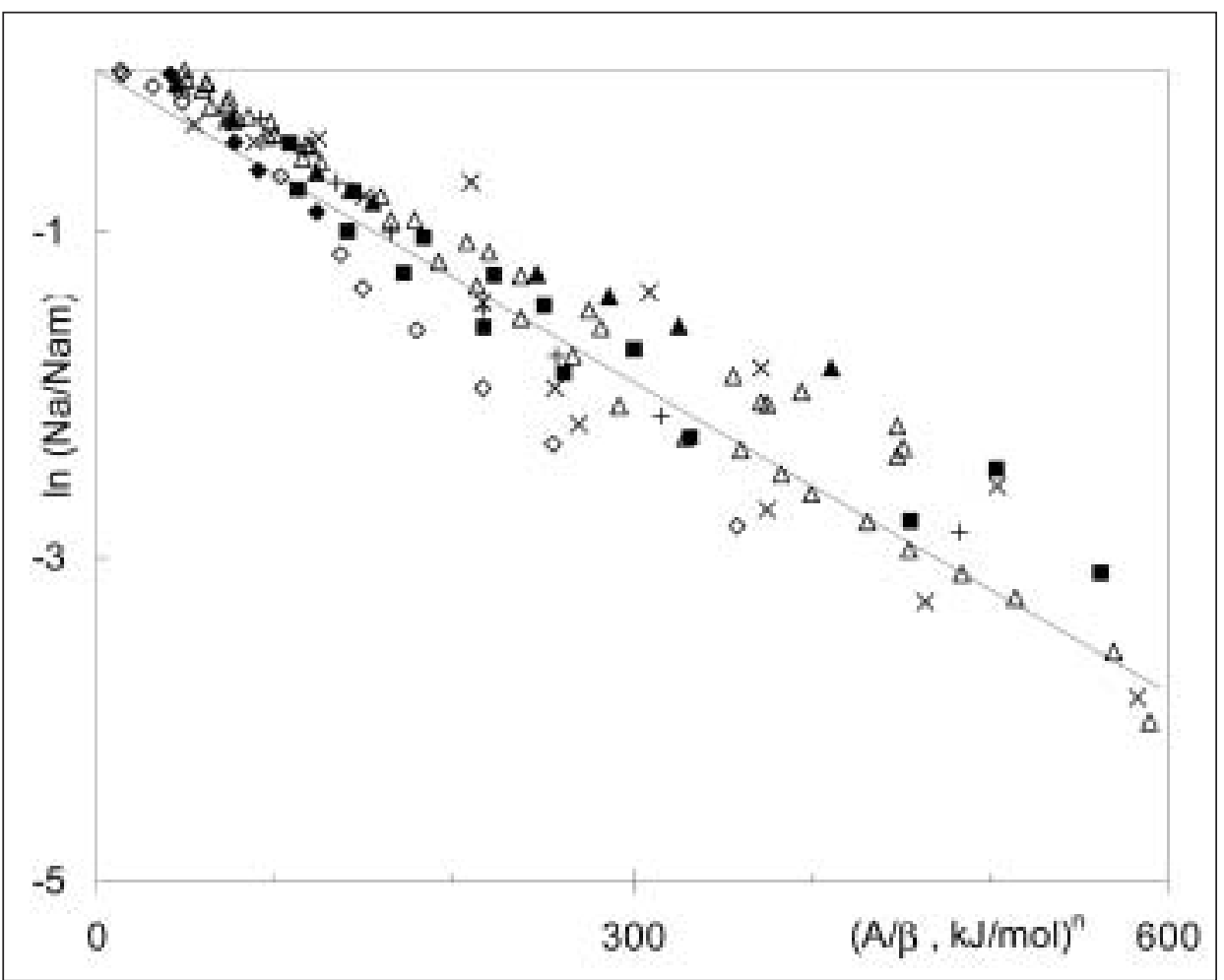

Fig. 3. The adsorption, on carbon blacks Hoechst of $\mathrm{N}_{2}(77 \mathrm{~K})(\diamond) ; \mathrm{CH}_{2} \mathrm{Cl}_{2}(293 \mathrm{~K})(+) ; \mathrm{C}_{6} \mathrm{H}_{6}$ $(282,293,311,323 \mathrm{~K})(\triangle)$ and $\mathrm{CCl}_{4}(293,305 \mathrm{~K})(\mathrm{x})$; and on Vulcan $3-\mathrm{G}$, of $\mathrm{N}_{2}(77 \mathrm{~K})(\bullet) ; \mathrm{CO}_{2}$ $(253,273 \mathrm{~K})(\boldsymbol{\square}) ; \mathrm{C}_{6} \mathrm{H}_{6}(293 \mathrm{~K})(\boldsymbol{\Lambda})$. Exponent $\mathrm{n}=2.1$ corresponds to the average obtained with Eqn. (6) and the reference is $\mathrm{E}_{\mathrm{C} 6 \mathrm{H} 6}=11.7 \mathrm{~kJ} \mathrm{~mol}^{-1}$. pattern for the adsorption of benzene and nitrogen by both porous and non-porous silicas.

In the case of the graphitised carbon blacks (Fig. 3), the same procedure leads to a single representation with an average value $\mathrm{n}=2$.1. It is significantly higher than for Cabosil and suggests that the energy distribution is narrower, as expected. With respect to benzene, where $\mathrm{E}_{\mathrm{C} 6 \mathrm{H} 6}(\mathrm{CB})=11.7$ $\mathrm{kJmol}^{-1}$, the affinity coefficients are $\beta_{\mathrm{N} 2}=$ $0.63, \beta_{\mathrm{CO} 2}=0.5, \beta_{\mathrm{CH} 2 \mathrm{Cl} 2}=0.71$ and $\beta_{\mathrm{CCl} 4}$ $=0.84$. These values are similar to those obtained for activated carbons [14] and in this case nitrogen conforms to the general pattern.

Finally, in the case of adsorption on rhombic sulphur [21][22][24], shown in Fig. 4, one obtains a single representation with an average value $\mathrm{n}=2$, which corresponds to the DRK model. As suggested by computer simulations for argon on the (111) face of rhombic sulphur [22], $\chi(\varepsilon)$ is a skewed distribution extending from -4 to $-12 \mathrm{~kJ} \mathrm{~mol}^{-1}$ with a maximum near $-7 \mathrm{~kJ}$ $\mathrm{mol}^{-1}$. This distribution was also found to be in good agreement with the evolution of the heat of adsorption [21][22]. In the present case, taking nitrogen as a reference, $\mathrm{E}_{\mathrm{N} 2}\left(\mathrm{~S}_{\alpha}\right)=2.55 \mathrm{~kJ} \mathrm{~mol}^{-1}$ leads to the affinity coefficients $\beta_{\mathrm{Ar}}=0.86, \beta_{\mathrm{CH} 4}=1.15$ and $\beta_{\mathrm{C} 5 \mathrm{H} 12}=4.3$.

\section{Conclusions}

The present study suggests that the characterization of surfaces based on the BET and the DRK models are complementary if one uses the BET monolayer capacities as references and a variable exponent $n$. The latter variable, corresponding to the modified DRK Eqn. (7), takes into account the degree of heterogeneity of the adsorption energy, $\chi(\varepsilon)$. It may vary considerable from one type of surface to another. This is illustrated by graphitised carbon blacks and by non-porous silicas, which are respectively more homogeneous and more heterogeneous that the distribution implied by the DRK model with exponent $n=2$. The latter corresponds to an 'average' heterogeneity.

The cases of nitrogen and benzene adsorbed by Cabosil also show that the heterogeneity may depend on the adsorptive and specific interactions.

The combination of the BET approach, which provides a reliable monolayer capacity, with the extended DRK Eqn. (7) leads therefore to a reasonable characterization of the surface by including the heterogeneity of the adsorption energy.

The study also shows that adsorption data for series of simple adsorbates can be 


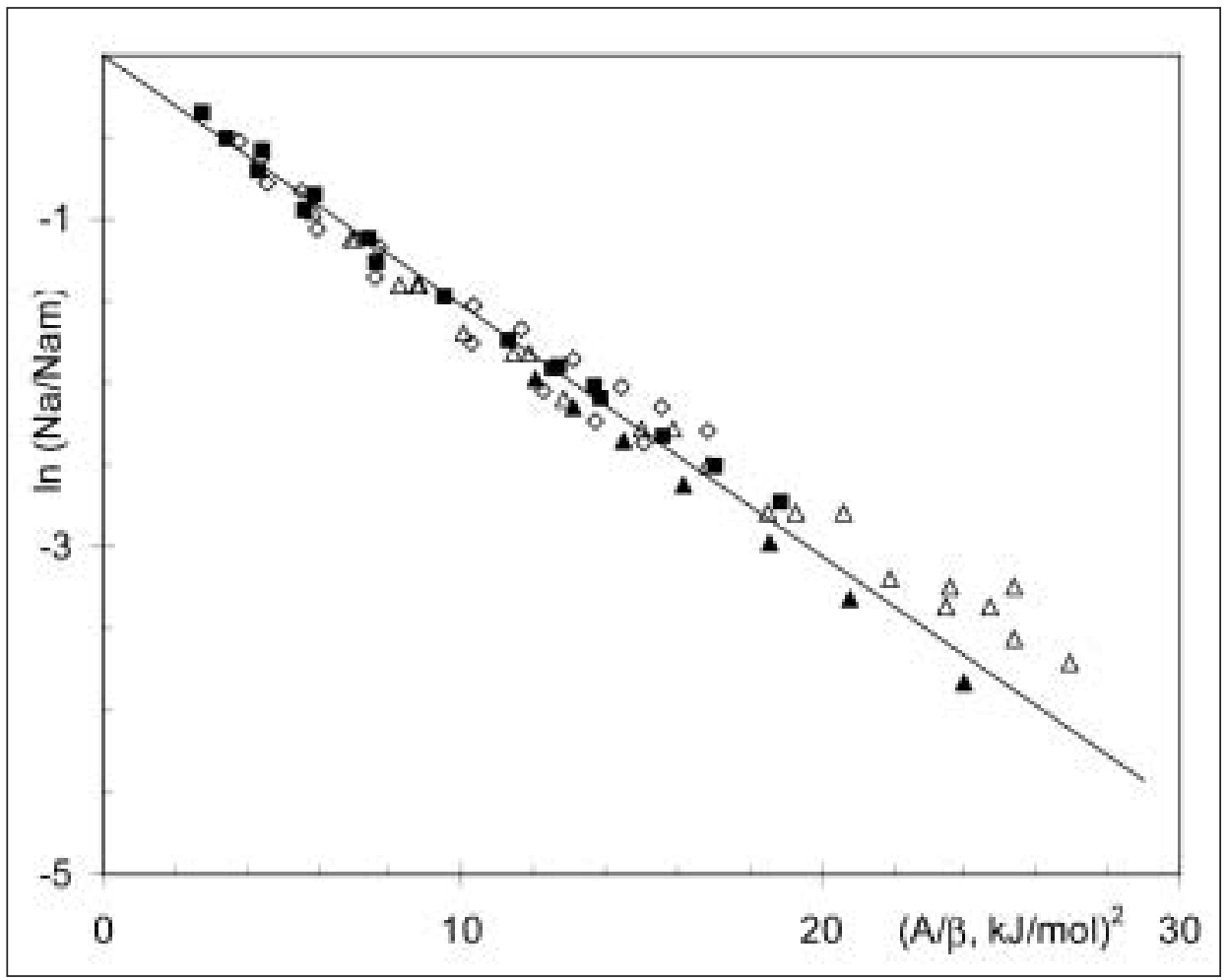

Fig. 4. The adsorption, on the (111) face of rhombic sulphur $\left(\mathrm{S}_{\alpha}\right)$, of $\mathrm{N}_{2}(77,86 \mathrm{~K})(\boldsymbol{\square})$; $\operatorname{Ar}(77,87$ $\mathrm{K})(\diamond) ; \mathrm{CH}_{4}(80 \mathrm{~K})(\boldsymbol{\Delta})$ and neo-pentane $(253,263,273 \mathrm{~K})(\triangle)$. Exponent $\mathrm{n}=2.0$ corresponds to the average obtained with Eqn. (6) and the reference is $E_{\mathrm{N} 2}(77 \mathrm{~K})=2.56 \mathrm{~kJ} \mathrm{~mol}^{-1}$. For clarity, a selection of data is shown.

Table. General characteristics of the gas-solid systems (CB corresponds to carbon blacks Hoechst and Vulcan-3G). Average values are given.

\begin{tabular}{llll} 
Solid & $\mathrm{SiO}_{2}$ (Cabosi) & $\mathrm{CB}$ & $\mathrm{S}_{\alpha}(111)$ \\
$\mathrm{S}_{\mathrm{BET}}\left(\mathrm{N}_{2} ; 77 \mathrm{~K}\right)\left(\mathrm{m}^{2} \mathrm{~g}^{-1}\right)$ & 210 & $53 / 73$ & 0.060 \\
$\mathrm{~N}_{\mathrm{am}}(\mathrm{BET}) / \mathrm{N}_{\mathrm{am}}(\mathrm{DRK})(\mathrm{n}=2)$ & 0.64 & 1.2 & 0.95 \\
$\mathrm{n}$ optimum, EQN (6) & $1.2\left(\mathrm{~N}_{2}: 1.8\right)$ & 2.1 & 2.0 \\
$\mathrm{E}_{\mathrm{N} 2}\left(\mathrm{KJ} \mathrm{mol}^{-1}\right)$ & 4.62 & 6.99 & 2.56 \\
$\mathrm{E}_{\mathrm{C} 6 \mathrm{H} 6}\left(\mathrm{KJ} \mathrm{mol}^{-1}\right)$ & 5.61 & 11.7 & - \\
\hline
\end{tabular}

fitted to a single DRK equation with the help of scaling factors (affinity coefficients). These factors depend on the surface and on specific interactions.

Received: July 14, 2003

[1] S.J. Gregg, K.S.W. Sing, 'Adsorption, Surface Area and Porosity', Academic Press, London, 1982.

[2] V.R. Deitz, H. Turner, in 'Surface Area Determination', Eds. D.H. Everett, R.H. Ottewill, Butterworth, London, 1970, p. 43.

[3] M.G. Kaganer, Doklady Akad. Nauk SSSR 1957, 116, 251.

[4] M.G. Kaganer, Doklady Akad. Nauk SSSR 1958, 122, 416.

[5] M.G. Kaganer, Hurnal Fiz. Khimii 1959, 33, 2202.
[17] N.N. Avgul, A.V. Kiselev, in 'Chemistry and Physics of Carbons' vol. 6, Ed. P.L. Walker, Marcel Dekker, New York, 1970, p. 1.

[18] M.M. Dubinin, F. Stoeckli, J. Colloid Interface Sci. 1980, 75, 34

[19] G.F. Cerofolini, J. Low Temp. Phys. 1972, $6,473$.

[20] W. Rudzinski, M. Jaroniec, L. Latjar, Wiadomosci Chem. 1976, 30, 305.

[21] H. Stoeckli-Evans, F. Stoeckli, Helv. Chimica Acta 1975, 58, 194, 2291.

[22] F. Sollberger, F. Stoeckli, Helv. Chim Acta 1974, 57, 2327.

[23] A. Guillot, F. Stoeckli, Carbon 2001, 39 2059.

[24] D. Morel, F. Stoeckli, W. Rudzinski, Surface Sci. 1982, 114, 85

[25] A. Pendleton, A.C. Zettlemoyer, J. Colloid Interface Sci. 1984, 98, 439.

[26] A. Pendleton, J. Colloid Interface Sci. 2000, 225, 105 .
[6] M.G. Kaganer, Doklady Akad. Nauk SSSR 1961, 138, 405.

[7] M.M. Dubinin, Carbon 1989, 27, 457.

[8] F. Stoeckli, in 'Porosity in Carbons-Characterization and Applications', Ed. J. Patrick, Arnold, London, 1995, p. 67.

[9] F. Stoeckli, Russ. Chem. Bull. Int. Ed. 2001, 50, 2265-2272.

[10] W. Rudzinski, D.H. Everett, 'Adsorption of Gases on Heterogeneous Surfaces', Academic Press, London, 1992.

[11] D.F. Klemperer, in 'Surface Area Determination', Eds. D.H. Everett, R.H. Ottewill, Butterworth, London, 1970, p. 55.

[12] F. Stoeckli, D. Hugi-Cleary, Carbon 2000, 38, 1309.

[13] M. Polanyi, Z. Elektrochem. 1920, 26, 371; Z. Elektrochem. 1929, 35, 431.

[14] G. Wood, Carbon 2001, 39, 434.

[15] A. Lavanchy, F. Stoeckli, Carbon 1997, 35,1573

[16] A.L. McClellan, H.F. Harnsberger, J. Colloid Interface Sci. 1967, 23, 577. 